\title{
Subalternidade e identidade regional da América Central
}

\author{
Aleksander Aguilar Antunes
}

\begin{abstract}
RESUMO: A relação centro-periferia que a América Central encarna em sua condição geopolítica não se dá a partir de uma essência: sistemicamente entendida como região, o lugar subalterno que lhe é atribuído converte-a na periferia que dá centralidade ao centro. Trata-se de um paradoxo semântico que produz sentido à própria lógica da economia política global. Neste texto, discutem-se algumas visões políticas sobre centroamericanidad em relação à construção de sua identidade regional e seus efeitos.
\end{abstract}

PALAVRAS-CHAVE: Identidade Regional. América Central. Subalternidade. Condição Ístmica. Lumpemregião.

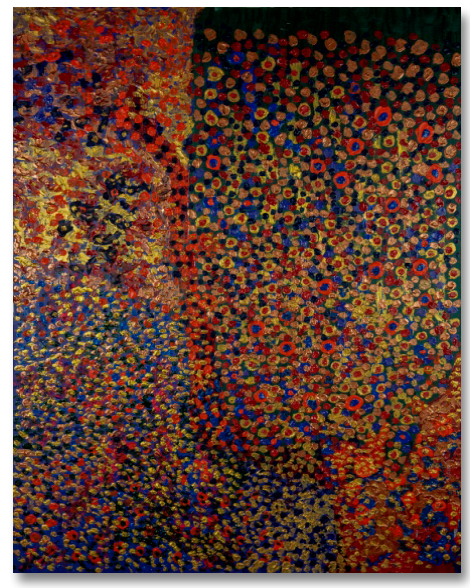

\section{Subalternity and regional identity of Central America}

\footnotetext{
$\overline{\text { Aleksander Aguilar Antunes }}$

Doutor em Ciência Política pela Universidade Federal de Pernambuco (UFPE). Fundador, coordenador e editor da rede-plataforma centroamericanista. O Istmo e membro do grupo de trabalho El istmo: repensando los centros, vinculado ao Conselho LatinoAmericano de Ciências Sociais (CLACSO). Pós-Doutor do programa Pueblos en Movimiento da Associação Latino-Americana de Sociologia (ALAS). Pesquisador visitante do Programa de Pós-Graduação em Política Social e Direitos Humanos da Universidade Católica de Pelotas (UCPel), no Brasil.

E-mail: antular@hotmail.com.
}

\begin{abstract}
The center-periphery relationship that Central America embodies in its geopolitical condition does not arise from an essence; systemically understood as a region, the subordinate place assigned to it converts it into the periphery that gives centrality to the center. It is a semantic paradox that produces meaning to the very logic of the global political economy. In this text, some political views about centroamericanidad in relation to the construction of regional identity and its effects.
\end{abstract}

KEYWORDS: Central America. Regional Identity. Subalternity. Isthmic Condition. Lumpenregion.

RECEBIDO EM: 24/02/2019

Aprovado EM: $26 / 08 / 2019$ 


\section{O centro (marginal) das Américas (do mundo)}

"La dulce cintura de América" (NERUDA, 2002);

"el marginal de la marginalidad" (ARIAS, 1995);

"la cola de Quetzacóatl" (BERGOINEG, 2001 apud ZAMORA, 2014).

São tão variadas quanto interessantes as analogias e as metáforas que podemos encontrar fazendo referência geográfica, política ou sociocultural aos territórios que, de forma acidentada e ondulante, cobrem de Tehuantepec, no sul do México, até o chamado Tapón del Darién, na fronteira norte da Colômbia, uma estreita superfície, entre os oceanos Atlântico e Pacífico, de pouco mais de 500 mil km², em pouco menos de dois mil quilômetros de extensão marcada por vulcões, selvas e lagos. Dessa singular constituição geofísica decorre uma formidável variedade de microclimas que podemos agrupar em três níveis ecológicos: as chamadas terras frias, das topografias altas e cadeias montanhosas vulcânicas; as terras temperadas, dos blocos de altiplanos de vales e terras férteis; e as terras quentes, de ambas as costas.

Sob tais características, essa "cauda de Quetzalcóatl" faz nesses limites fronteiriços um heterogêneo particular: começa por representar uma "geografia da desgraça" (BRIGNOLI, 2010, p.18), porque terremotos, erupções e furacões conformam eventos que, há séculos, são parte desse espaço e da vida dos povos que o habitam. Esses têm raízes diversas e profundas que remontam às grandes civilizações pré-colombianas e outros grupos étnicos por elas influenciados que hoje são chamadas de mesoamericanas conformadas principalmente por culturas maias, olmecas e toltecas - e também por grupos de origem chibchas.

1 Quetzalcóatl é uma divindade das culturas mesoamericanas cujo nome significa "serpente emplumada" (de quetzal, nome comum do pássaro Pharomachrus mocinno, e do nahuat cóatl, serpente). Representa as energias telúricas que ascendem; daí a sua representação como uma serpente emplumada. Nesse sentido, representa a vida, a abundância da vegetação, o alimento físico e espiritual. 
Como na maior parte de Abya Ayala², esses territórios foram devastadoramente afetados pela conquista colonial. Hoje, contudo, de toda a América Latina, são os territórios centro-americanos em específico os que ainda são particularmente abalizados e atacados por processos de ingerências políticas externas, sempre presentes, obrigando seus povos a sua defesa que lhes valem a caracterização como espaço de convulsão social constante (CASTAÑEDA; VALENZUELA, 2015).

Enquanto região - termo que destacamos, porque o problematizaremos a seguir - sua posição entre mares e continentes tem, ao longo de sua história, marcado sincrônica e diacronicamente, as construções e as percepções de uma identidade regional e permitido gerar uma variedade de ordenamentos políticos nos atuais Estados-nação, inventados no século XIX, que hoje a conformam e que, com recorrentes ausências e negligências, buscam estabelecer sua centroamericanidad. ${ }^{3}$

Esse entendimento sobre tal 'condição ístmica' (BERGER, 2017) é compartilhado por uma diversidade de intelectuais centroamericanos ou centro-americanistas - tais como Torres-Rivas (1981; 2011), Granados-Chaverri (1985), Cuevas-Molina (2006; 2012), Silva-Hernández (2006), Brignoli (2010) e Cardenal (2014) que contribuíram para uma caracterização geral de aspectos sociopolíticos nesses territórios que hoje, a depender do critério adotado, chamamos de Centroamérica. ${ }^{4}$ Desde antes da conquista colonial,

2 Palavra no idioma do povo Kuna-Panamá que dá nome à territorialidade do continente americano na maneira como foi definido por uma pluralidade de povos articulados em cúpulas continentais indígenas. Abya Yala é o nome dado ao continente hoje conhecido como América, em sua extensão do Alasca à Patagônia, antes da chegada de Cristóvão Colombo e dos europeus. Corresponde à "terra madura", "terra viva" ou "terra em florescimento".

3 Conhecimento compartilhado de sentimento de pertença que caracteriza a América Central como uma casa común (SILVA-HERNÁNDEZ, 2014).

4 Comumente, Centroamérica é, em termos de história sociopolítica, uma especificidade da América Central geográfica, pois faz referência aos cinco países que conformaram a unidade político-administrativa no período colonial da região, como veremos mais detalhadamente à continuação do texto. É a maneira mais corrente de ser diferenciada do que se considera a atual América Central em sentido amplo (que além dos cinco países, inclui Belize e Panamá e, no caso do chamado SICA-8, inclusive a República Dominicana). Neste texto, dado que a nomeação do território é, precisamente, uma questão que faz parte dos temas aqui abordados, utilizaremos indiscriminadamente um e outro termo, 
suas sociedades nunca formaram parte de uma univocidade sociopolítica e a pluralidade cultural sempre existiu: "Centroamérica es un territorio en el que se cruzan múltiples tradiciones y culturas. En ella se encuentran presentes tendencias orientadas tanto a la disgregación como a la unión" (CUEVAS-MOLINA, 2006, p. 61).

De todas aquelas terras que o conquistador inicialmente chamou de Novo Mundo, para logo batizá-las de Américas, apenas essa porção carrega a particularidade de istmo entre oceanos e ponte entre continentes. Essa dupla condição, uma das suas características mais marcantes, condiciona e condicionou a dinâmica política, econômica, social e cultural dos povos que habitam esses territórios, desde antes do jugo imperial espanhol, tal como argumentaremos com mais detalhe ao longo deste texto.

Ainda assim, as caraterísticas sociopolíticas da chamada América Central - embora inscrita no que entendemos como América Latina, área que mobiliza poderosos interesses econômicos, políticos e acadêmicos em especial nestas primeiras décadas do século XXI - dão-se num lugar periférico tanto do sistema internacional como das Ciências Sociais. A localização geoestratégica do istmo da América Central, contudo, condicionou sua história e é crucial para pensá-lo no presente e elucidar sua projeção para o futuro o que, mesmo apenas a partir das lentes da geopolítica tradicional, explica porque se trata de um espaço merecedor de análises densas e particulares.

Esse local específico que ocupa na geografia do continente determina a intensidade com que tem ocorrido na região uma série de fenômenos, tais como o deslocamento violento de povos originários de seus territórios ancestrais; o estabelecimento de regimes autoritários, seja de caráter militar (Guatemala, Honduras, El Salvador), seja por dinastias familiares (Nicarágua); a eclosão da chamada crise da América Central como resultado político dos conflitos armados que dividiram as sociedades centro-americanas

pois assumir tal diferença poderia confundir-se com afiliação tácita, ao fim e ao cabo equivocada, a uma única lógica de nomeação. De todo modo, por se tratar de uma distinção que, sob quaisquer efeitos, não se dá em português, usaremos a expressão Centroamérica como na grafia em espanhol, sem necessidade a partir desse ponto, portanto, de marcação da palavra em itálico. 
em dois, durante as guerras civis entre as décadas de 1960-1990; e a expressão da incapacidade das elites dominantes para resolver as contradições de um capitalismo periférico. No mesmo período, houve também o surgimento de um poderoso movimento popular contra hegemônico e de oposição que encontrou a escalada de terrorismo do Estado e de contra insurgência em resposta às suas reivindicações democráticas legítimas; o ataque neoliberal em dia com o estabelecimento da hegemonia do discurso da globalização que veio das mãos dos Acordos de Paz, tendo como consequência o desenvolvimento de uma série de avanços na democracia procedimental que não contribuíram para diminuir a extrema polarização social da região e, ao contrário, demonstram ter aprofundado a desigualdade e a conflitividade social, durante as primeiras décadas dos anos 2000.

A globalização em sua fase atual tem uma dimensão social e espacial específica e particularmente relevante: os grandes corredores comerciais. Estes fazem com que as antigas rotas de comércio agora sejam espaços transnacionais, modernos, mas ambíguos, territórios de intenso tráfego e em constante disputa. Um dos corredores mais importantes da América Latina atravessa seu ponto mais estreito: O Istmo centro-americano. Na prática, conecta duas áreas de enorme desenvolvimento social e produtivo: o Atlântico e o Pacífico. Em toda a área conhecida como a Grande Bacia do Caribe, as políticas públicas atualmente estão focadas em construir enormes e ambiciosas infraestruturas de trânsito e exportação: a expansão do Canal do Panamá, o projeto do Canal da Nicarágua, a construção dos portos de Colón, Kingston e Mariel (com financiamento brasileiro), etc. Além disso, adquire centralidade a promoção da agroindústria expansiva (óleo de palma, abacaxi, plantações florestais, entre outros) e de outros grandes projetos de exploração de recursos naturais, principalmente nas mãos de corporações transnacionais (mineração, exploração de petróleo, hidrelétricas).

O antigo Plano Puebla-Panamá, hoje denominado Proyecto Mesoamérica (PM), é um caso emblemático desse modelo de desenvolvimento. Diferentemente do Sistema de Integração Centro-americano (SICA) o processo sistêmico e institucionalizado 
da integração regional na América Central- apesar de alvo e merecimento de diversas criticas sobre sua morosidade e interesses possui mais de 50 anos com metas progressivas em dimensões econômicas, políticas e sociais. O PM é um esquema de cooperação intergovernamental que inclui formas de participação do setor privado com foco na infraestrutura e em serviços, deixando secundarizado, a pesar de retórica oficial contrária, ${ }^{5}$ as comunidades locais, especialmente as camponesas e as originárias. Suas obras costumam ser implementadas sem consulta prévia aos que serão afetados em seus direitos econômicos, sociais, culturais e ambientais: "Integra a gobiernos, empresas y fuerzas de seguridad, al tiempo que socava la democracia al marginar y alentar o forzar el desplazamiento de los pobladores, e incluso su emigración internacional" (BALLINA, 2011, p. 140).

O Plan Puebla-Panamá (PPP) é o antecedente direto do PM que, pelo aumento de investimentos, representou efetivamente uma melhora na infraestrutura de comunicações e de transportes na zona, mas segue havendo também uma alta marginação socioeconômica dos habitantes da região, dado que a exploração dos recursos naturais resulta ter centralidade no projeto, em lugar da sua conservação, conforme o discurso oficial. A partir de 2008, a legitimidade da atualização do PPP em PM tem por base um argumento histórico, em que o conceito de Mesoamérica, articulado pelo antropólogo Paul Kirchhoff nos anos 1960, serve de terreno. Em outras palavras, o PM é 'vendido' como um tratado entre países que conformam uma região pelo fato de compartilhar uma história, espaço e traços culturais comuns. Por isso, suas aspirações e interesses também são comuns: a iniciativa conjunta não é apenas válida, senão necessária, para superar os graves problemas sociais que lhe afeta enquanto região.

É surpreendente que toda essa projeção não aponte para uma superação do modelo primário-exportador latino-americano, mas sim para uma consolidação dele, com as nuances da predominância do capitalismo financeiro. O impacto regional e estrutural dessas obras está sendo e será muito considerável em várias áreas das sociedades centro-americanas, em especial.

5 "Cf. site de Proyecto Centroamérica. 
No entanto, no estudo da América Central de forma marginal ou omissa, como normalmente ocorre, deixa-se de discutir, problematizar, comparar e compreender tais especificidades que são de fundamental atenção por se fazerem, com frequência, anunciadoras de mudanças fundamentais e de ampliação de entendimentos gerais de toda a América Latina (CASTAÑEDA; VALENZUELA, 2015). Podemos visualizar essa afirmação, por exemplo, com o ter sido campo de experimentação de alguns dos principais debates sobre desenvolvimento após a Segunda Guerra Mundial, primeiro com as propostas estruturalistas da CEPAL $^{6}$ e, logo, com as neoliberais do Consenso de Washington (CALDENTEY, 2010), com o haver funcionado como laboratório da modernidade (SALAMANCA, 2014) no passado colonial e sê-lo das articulações hegemônicas das elites no presente neoliberal (FUENTES-KNIGHT, 2015). Tal situação é exemplo da implicação dos territórios centro-americanos numa relação entre subalternidade/identidade regional que conceitualmente buscaremos explicitar e problematizar neste artigo, iniciando por sugerir seus pontos de contato, a partir das raízes de sua história política enquanto 'região'.

\section{0 nome e o nomear do centro das Américas}

Cinco Estados-nação (Guatemala, El Salvador, Honduras, Nicarágua e Costa Rica) se formaram logo da independência da Espanha, em 1821. São os territórios que historicamente conformaram uma única unidade político-administrativa no período colonial, a denominada Capitania General de Guatemala. Essa história configura critério certamente válido para fazer referência e cristalizar o termo Centroamérica histórica, na cúpula de chefes de Estado Tuxtla-Gutiérrez II, como uma definição metodológica e um fato político. Ainda assim, como afirmamos anteriormente, a alusão ao vocábulo Centroamérica não faz referência a uma entidade regional unívoca e unitária. Há um rol de possibilidades de nomeações:

6 Destacamos o Mercado Comum Centro-Americano (MERCOMUN), por exemplo, como a primeira experiência do projeto de Industrialização por Substituição de Importação (ISI) da Comissão Econômica para América Latina (CEPAL) para a região; marco da história de integração regional na América Latina. 
- Sistema da Integração Centro-Americano (SICA): além dos cinco Estados ístmicos "históricos", inclui Panamá, Belize e, mais recentemente, a República Dominicana, apesar desta não estar localizada no território ístmico;

- Triângulo Norte: que se refere a El Salvador, Guatemala e Honduras, por compartilharem análogos padrões de desenvolvimento com problemas estruturais semelhantes, especialmente em termos de segurança regional;

- CA-4: que além dos três Estados que conformam o chamado Triângulo Norte, inclui a Nicarágua para efeitos de políticas fronteiriças baseadas em acordos entre si;

- Mesoamérica: que deixou de ser apenas um conceito histórico-antropológico e assumiu sentido nos termos da geopolítica tradicional, em que os países situados entre o Panamá e o México - com esses dois incluídos - compartilham entre si uma relação estrutural com a potência do Norte, os Estados Unidos;

- Grande Bacia do Caribe: nos marcos geopolíticos expandidos, pode incluir à seção ístmica também o conjunto das ilhas do Mar das Antilhas.

Em termos de identidades étnico-culturais também é possível visualizar determinadas zonas em áreas específicas. São traços, valores e tradições que se diferenciam a partir do estabelecimento de uma cultura ocidental que se fez dominante, ao longo de centenas de anos, desde a chegada dos conquistadores europeus, no século XVI, e impediu o desenvolvimento próprio desses espaços. Nesses termos, Cuevas-Molina (2006) identifica três e Brignoli (2010) quatro grandes áreas culturais:

- Centroamérica indígena: onde o caso paradigmático é o do Guatemala, com mais da metade da população sendo descendente de indígenas mesoamericanos, principalmente maias;

- Centroamérica crioula e mestiça: do sul da Guatemala, passando pelas terras altas de Honduras e El Salvador, até o norte da Costa Rica, de traços que misturam a ancestralidade maia com os da imigração espanhola; 
- Centroamérica mestiça e "branca": onde o peso da herança espanhola é mais facilmente reconhecível, especialmente nas grandes cidades da região. O caso paradigmático é a região do Valle Central, zona de Cartago, na Costa Rica;

- Centroamérica negra: zona de cultura de enclave em toda a costa do Caribe do Istmo, desde Belize até o Panamá, de selvas tropicais e de universos das plantações bananeiras das companhias estadunidenses que importaram mão-de-obra especialmente da Jamaica, dando-lhe características culturais próprias.

Diante das percepções externas, a América Central é quase by default uma região, inegável conjunto de pequenos países muitas vezes visto como exóticos, cuja localização entre dois oceanos parece marcar irremediavelmente o seu destino. Para seus povos, contudo, a percepção dessa identidade regional oscila em um cotidiano sensível a uma variedade de fraturas nessa lógica que, se bem com longa história que a justifique, é externamente concebida e discursivamente articulada.

A partir da Conquista, podemos sistematizar, grosso modo, a história política centro-americana nas etapas da: era colonial para a independência da Espanha; desta para uma efêmera anexação ao 'império constitucional mexicano' de Agustín Iturbide (dezembro de 1821 a junho de 1823); e, então, desta para a conformação de uma federação centro-americana que, em sua dissolução, deu passo para os Estados-nação, consonante às antigas províncias coloniais que integraram esse curto governo federal de quinze anos, de 1823 a 1838. Ainda assim, mesmo que a República Federal de Centroamérica tenha tido uma vida breve e também altamente convulsionada (CARDENAL, 2014), ela é uma característica histórica que demarca uma sonora diferença com o resto do continente latino-americano em termos de fundamentos, que vem, desde o período colonial, da ideia de pertencimento a uma mesma unidade e, portanto, de identidade regional. 
Do final do século XIX até os dias atuais - passando pela importância do nome de Francisco Morazán ${ }^{7}$ nesse período como pivô da força das ideias unionistas centro-americanas -, temos a alcunha de Repúblicas bananeras pejorando os Estados centro-americanos. Esse nome tem origem no estabelecimento de companhias norte-americanas na região que eram especializadas no cultivo e na exportação da fruta e que, associadas às oligarquias locais, promoveram um tipo de desenvolvimento econômico venal no contexto de países empobrecidos, governados por elites autoritárias (QUESADA-MONGE, 2013).

No avançar do século XX, embora a banana tenha se mantido como um importante produto das exportações da região, bem como outros produtos primários, ${ }^{8}$ chegamos ao século XXI com as maquilas ${ }^{9}$ como o símbolo de outro momento da sua história político-econômica, que perpassa e é perpassada por amplas transformações socioculturais que têm lugar no O Istmo como parte da sua irrupção, em condições periféricas e subdesenvolvidas, no sistema capitalista neoliberal globalizado (CUEVAS-MOLINA, 2012). A transformação de Centroamérica em repúblicas maquileras carrega justamente o fardo da pesada herança que suas recentes guerras civis representam para a região, as quais deixaram

7 O general Francisco Morazán foi um dos principais nomes do unionismo centro-americano. De acordo com Cardenal (2014), o período imediato pósindependência esteve marcado por dois períodos de intensas guerras civis: (a) de 1826 a 1829, e (b) de 1830 a 1842 . A percepção das elites de cada província nesse período convulsionado de transições de ordens políticas era de que as tentativas federais representavam uma ameaça a suas soberanias locais. Morazán, que se iniciou na política regional como secretário executivo da província de Honduras, sendo celebrado até hoje, esteve fundamentalmente ligado a mais esse período de singular confusão política pelos seus reiterados intentos de compor um exército federal e garantir a integridade territorial centro-americana.

8 Em particular, café e açúcar, o que levou Brignoli (2010, p.38) a denominar as economias centro-americanas como "economías de postre".

9 Grosseiramente, as maquilas representam formas de produção de empresas que importam materiais, sem pagar impostos. Seu produto não se comercializa no país em que é gerado, mas é parte de uma cadeia transnacional de produção ou serviço de suporte a companhias também transnacionais. Na América Latina, o México é o país com maior número de maquilas, sobretudo na área dos têxteis. A América Central, pós-1990, tem enveredado pelo mesmo caminho. Funcionam, majoritariamente, com capital estrangeiro e os produtos montados são vendidos de volta ao país de origem das matérias-primas. Há, no entanto, fortes críticas ao modelo, que evidenciam a precarização laboral, as altas jornadas de trabalho e os baixos salários (CUEVAS-MOLINA, 2012). 
cicatrizes ainda abertas no corpo social centro-americano. Situála, portanto, em um contexto hodierno passa por afirmar a conjuntura do pós-guerra na região, embora não a limitar a isso.

As guerras civis centro-americanas do século XX, entre as décadas de 1960-1990, principalmente, conformam uma fase avassaladora da história do istmo, de profundas crises sociopolíticas e econômicas, cujas consequências constituíram-se como um fundamental e atual marco de características comuns e sentidos de centroamericanidades (TORRES-RIVAS, 2011; ERCA, 1999; BAVIC, 2010; GARITA, 2012; 2013). Nesse período, manifestaram-se em Centroamérica, de forma concentrada e radical, não apenas as contradições econômicas e sociais que já arrastava historicamente, mas também os interesses opostos dos grandes blocos do poder mundial que marcaram grande parte do século passado. O conjunto da região, não apenas em Nicarágua, El Salvador e Guatemala, como afirma o historiador francês Olivier Dabène (2009), conheceu um período que lhe deixou uma marca indelével. As guerras foram devastadoras de amplos extratos da cidade e do campo.

A violência ${ }^{10}$ e as migrações ${ }^{11}$, poderosos traços que caracterizam a região hoje, têm como uma de suas causas primordiais

10 A América Central atual vive uma nova crise de segurança regional, hodiernamente marcada pela ação de cartéis do narcotráfico, associados ao avassalador e tipicamente problema centro-americano das maras/pandillas - principal expressão dessa crise de segurança - que existem e se fortalecem justamente nas brechas/ausência de força do Estado em responder às demandas por mais segurança. A assinatura dos Acordos de Paz coincidiu com políticas estadunidenses de deportação em massa de prisioneiros centro-americanos. Um percentual significativo de homens e mulheres que haviam sido criados e curtidos nas ruas e gangues estadunidenses foi mandado de volta a seus países de origem e acabou agindo como pontos focais das gangues americanas, recriando toda a estrutura delitiva em países destruídos por guerras com instituições sucateadas e um sistema de justiça, em que a corrupção garante a impunidade. Esses elementos fazem a América Central ser considerada a região mais violenta do mundo (AGUILAR ANTUNES; VITORINO, 2013).

11 As migrações na América Central se sucederam em diversas fases da sua história e por diversas razões, mas contemporaneamente tiveram causas particulares: as principais, desde a segunda metade do século XX, são as político-econômicas, que produziram movimentos de expulsão de grandes contingentes de população nativa dos seus lugares de origem em direção a países onde acreditam que terão mais segurança e melhor nível de vida. As transformações culturais que este fenômeno acarreta são profundas, ao ponto de El Salvador, por exemplo, um dos países centro-americanos que com mais 
essas guerras. Logo, a noção de uma identidade regional centro-americana é constituída lentamente, considerando o ritmo das identidades nacionais. Ela foi também redefinida várias vezes, ao longo do tempo, e seguramente deverá redefinir-se novamente no futuro, sobretudo com a emergência da Centroamérica negra e, principalmente, da Centroamérica indígena.

A partir do que sustenta Nora Garita (2012), entendemos que a independência do dos países centro-americanos do Império da Espanha rompeu com o seu status de colônia, mas inaugurou neles sua colonialidade (QUIJANO, 2000). O grito das elites crioulas serviu para desatarem-se da metrópole, mas também para silenciar as vozes populares e construir processos de invisibilização da exploração indígena e da escravidão africana, assim como de ocultamento das mulheres na vida social. Na construção dos Estados-nação do século XIX, as oligarquias estabeleceram os seus próprios interesses como sendo o interesse nacional. A seleção do perfil ideal de cidadão foi costurada no tecido do pensamento colonial, classificatório e racista e a construção do nacional deu-se junto à produção simbólica de exclusão, com o consequente estabelecimento de desigualdades sociais.

A seguir, um breve repasso dos conceitos de colonialidade/ descolonialidade para uma melhor compreensão dessa reflexão.

\section{Do pós-colonialismo à descolonialidade}

o século XX foi palco de profundas transformações multifacetadas ao redor do globo, de caráter político, econômico e social (a rigor, dimensões nunca efetivamente separáveis). Destacamos a importância da descolonização de territórios na África e na Ásia, a partir do fim da Segunda Guerra Mundial, como um momento

intensidade vive esta situação, ter chegado a estabelecer como política cultural do Estado a construção de uma identidade transnacional que compartilhe traços com a nacional. As migrações hoje originaram uma Centroamérica distante, um conglomerado dos los de afuera, que vivem em contextos multiculturais de hispanos nos Estados Unidos e conformam essa extensão cultural sui generis. Quando falamos de cultura centro-americana, devemos necessariamente levar em consideração as expressões destes grupos marcados pelo nacional e em contato com outros padrões identitários(AGUILAR ANTUNES; VITORINO, 2013). 
marcante do ponto de vista geopolítico, pois assinalou uma drástica mudança no cenário internacional. Em linhas gerais, portanto, os estudos voltados a este novo cenário mundial, em diversas áreas, tomaram corpo até constituir-se como uma nova corrente teórica.

Tal mudança demandou uma reflexão crescente dos regimes coloniais e das consequências então desconhecidas dos fenômenos que viriam a emergir nesse período, que se deu a conhecer como pós-colonial. É importante ressaltarmos que, nesse termo, o prefixo "pós-" não significa um momento atual que superou o período anterior, colonial, uma vez que "o fim do colonialismo enquanto relação política não acarretou o fim do colonialismo enquanto relação social, enquanto mentalidade e forma de sociabilidade autoritária e discriminatória" (SANTOS, 2004, p. 37). Sendo assim, o pós-colonialismo é atualmente assumido como um conjunto de reflexões capaz de teorizar sobre a grande quantidade de atores, dinâmicas e urgências que têm estado de fora das concepções hegemônicas da área, evidenciando o pensamento do chamado Sul Global. ${ }^{12}$ A acepção que constitui o pós-colonialismo pressupõe a revisão crítica da história contada em termos de modernidade ocidental e a identificação de um presente ainda permeado por uma série de discursos, práticas e relações políticas que confluem na perpetuação da distribuição assimétrica do poder e da riqueza no mundo.

A modernidade/colonialidade é um conceito que faz referência a um projeto de pesquisa de mesmo nome, criado no final dos anos 1990, por latino-americanistas em universidades estadunidenses. Esse projeto se assenta em uma reflexão central: a colonialidade não é um estado de coisas que se opõe à modernidade

12 O termo Sul Global passou a ser adotado com frequência para se referir a países quando o termo "terceiro mundo" caiu em desuso. Devemos, porém, atentar para o fato de que o referido "sul" não diz respeito a uma entidade geográfica, tampouco a um tipo ideal (MORIN, 2011). Os "sus" são muitos e estão por toda parte: no Sul global, no Norte, em nós mesmos. De acordo com o Programa das Nações Unidas para o Desenvolvimento (PNUD), o termo "Sul" faz referência ao coletivo de países em desenvolvimento que compartilham uma série de desafios e vulnerabilidades em nível internacional, sem que isto implique que todos pertençam a uma mesma categoria de desenvolvimento econômico, político ou social. 
e a precede, mas, como vimos, é parte integrante dos mesmos processos de modernização. Em uma relação direta entre uma e outra, a modernidade ocidental teve, ao longo de sua constituição, a co-presença da colonialidade.

Estabeleceram-se como uma das mais importantes contribuições ao pensamento latino-americano no século XXI, as reflexões e desdobramentos do grupo Modernidade/Colonialidade, tendo como motivação a discussão sobre as heranças coloniais na América Latina, em diálogo com a análise do sistema-mundo de Imannuel Wallerstein (1990). O projeto denuncia a lógica da colonialidade existente nas relações sociais, políticas e econômicas que tiveram início na colonização das Américas no século XVI e se perpetuam até o momento. Os países da América Latina, assim, passaram por uma descolonização, mas não por uma descolonialidade: "La colonialidad se refiere a la continuidad de las formas de dominación y explotación después del fin de las administraciones coloniales, producidas por las estructuras y culturas hegemónicas del sistema-mundo/capitalista-patriarcal/Moderno-Colonial" (GROSFOGUEL, 2007, p. 110).

Mignolo (2003) afirma que Quijano (1992; 2000) foi quem introduziu o conceito de colonialidade como o lado invisível e constituinte da modernidade - essa forma de dominação político-econômica e jurídico-administrativa das metrópoles europeias sobre suas colônias que, mesmo com o fim da colonização, se mantém presente nos esquemas culturais e de pensamento dominantes. Essa forma de dominação tem no conceito de raça o seu núcleo estruturante: o europeu posto como ente racial superior aos nativos colonizados e com uma estrutura de pensamento também superior a estes. Historicamente, houve uma densa conexão entre o colonialismo e o racismo, portanto, foi na estratégia de inferiorização do colonizado imposta pelo colonizador que a dominação de populações e territórios inteiros tornou-se possível. Conforme percebeu Franz Fanon (1965, p. 48), essa dominação não se embasou apenas na força militar, ao afirmar que: "não é possível submeter à servidão aos homens sem inferiorizá-los parte por parte, [...] o racismo não é mais que a explicação emocional, afetiva, algumas vezes intelectual, desta inferiorização". 
Uma vez reconhecida a colonialidade, o próximo passo é o de desprendimento (QUIJANO, 1992), conceito que Mignolo (2007) atribuirá a seu projeto de mudança epistemológica sob o nome de delinking. A descolonização também se faz através de discursos que interrompem um dito e o colocam em outro lugar, diferente do supostamente evidente, isto é, recuperando suas condições de produção. Para o caso latino-americano em particular, isso significa assumir uma compreensão crítica da chamada diferença epistêmica (MIGNOLO, 2003). na formação/transformação do sistema-mundo moderno/colonial, que estabelece uma relação importante entre histórias locais e produção de conhecimento. As principais referências de análise das Ciências Sociais formaram-se com base em conceitos como poder, hegemonia e economia política, os quais, em concreto, são construções históricas da modernidade europeia e não globais (ESCOBAR, 2010). Em outras palavras:

[...] "América Latina" es una consecuencia y un producto, de la geopolítica del conocimiento, esto es, del conocimiento geopolítico fabricado e impuesto por la "modernidad", en su autodefinición como modernidad. En este sentido, "América Latina" se fue fabricando como algo desplazado de la modernidad, un desplazamiento que asumieron los intelectuales y estadistas latinoamericanos y se esforzaron por llegar a ser "modernos" como si la "modernidad" fuera un punto de llegada y no la justificación de la colonialidad del poder. (MIGNOLO, 2003 apud WALSH, 2012, p. 01).

A teoria descolonial, a rigor, é crítica ao pós-colonialismo ${ }^{13}$ por considerar, entre outras razões, que sua reflexão está aferrada às experiências das ex-colônias britânicas. De certa forma paradoxalmente, a teoria pós-colonial tem sido desenvolvida principalmente nas academias de língua inglesa do Norte Global e com foco

13 Podemos encontrar uma leitura sobre a recepção do pós-colonialismo na América Latina, com reflexões de suas implicações teóricas e análises de suas aplicabilidades na compreensão do presente e do passado do continente, em Moraña, Dussel e Járegui (2008) e também em Salvatore (2010). 
nos processos de colonização e descolonização dos séculos XIX e XX na Ásia, África e Oriente Médio, chegando à região caribenha, como a geografia mais próxima da América Latina, quase sempre, porém, com o olhar posto apenas no mundo anglo-francófono daquela zona.

$\mathrm{Na}$ América Latina, entretanto, o colonialismo iniciou-se no período das grandes navegações ibéricas, das quais a própria modernidade europeia surgiu para estabelecer o sistema-mundo (MIGNOLO, 2003; 2007). São séculos, portanto, de lutas emancipatórias latino-americanas que hoje encontram, na globalização neoliberal, uma espécie de representação hodierna daquele antigo colonialismo no continente. Assim, nas últimas duas décadas do século XX e no início do século XXI, passa a ser formada uma crítica ao eurocentrismo, também por parte dos saberes silenciados e subalternizados, próprios da Abya Ayala. Logo, a subalternidade faz-se um conceito-chave para a apreensão das articulações teóricas que proponho neste trabalho, o que também exige sua breve apresentação.

\section{Origens, críticas e desdobramentos do pensamento subalterno}

A noção de subalternidade foi o gatilho de uma reflexão que, ao ser problematizada e sistematizada por uma ótica latino-americana, passa a ser chamada de descolonial. A origem é o chamado Grupo de Estudos Subalternos, formado na Índia, nos anos 1980, por um coletivo de historiadores sul-asiáticos, liderados por Ranajit Guha, que se dedicou a analisar criticamente não só a historiografia colonial da Índia feita por ocidentais europeus, mas também a historiografia eurocêntrica nacionalista indiana, avançando para o estudo de outras sociedades pós-coloniais. Seu livro Elementary Aspects of Peasant Insurgency in Colonial India (GUHA, 1999), originalmente publicado em 1983, foi declarado o manifesto dos Estudos Subalternos.

Inspirados por essa perspectiva, em 1993, John Beverley, Robert Carr, José Rabasa, Ileana Rodríguez e Javier Sanjinés fundaram, nos Estados Unidos, o Grupo de Estudios Subalternos 
Latinoamericanos. No avançar daquela década, parte do grupo passa a refutar a noção de que a análise da subalternidade seria uma crítica pós-moderna. Assim entendida, sem problematizar a noção de subalterno, os Estudos Subalternos não passariam de uma crítica ao eurocentrismo que não deixa de ser eurocêntrica, dado que o próprio conceito de "subalterno" foi tomado pelo grupo original indiano do trabalho do italiano Antonio Gramsci (LUDDEN, 2002). Contudo, o termo subalterno foi retomado para referir-se a grupos excluídos de sociedades, entendidos como de menor nível por causa de sua raça, etnia, classe social, gênero, orientação sexual ou religião.

Foi a partir do pensamento de Marx que Gramsci formulou o conceito de subalterno, como uma substituição ao termo "proletário", nos seus famosos cadernos do cárcere. Gramsci utiliza três acepções principais para o termo, a saber:

Em primeiro lugar, o termo é usado
em relação às camadas populacionais
desagregadas, politicamente (e, portanto,
também culturalmente), marginais, que
Gramsci julga "às margens da história".
Contiguamente a esta tematização, no
mesmo Caderno 3, se propõe um leque de
modalidades diversas do ser "subalterno"
que indica claramente a possibilidade de um
nível crescente de politização e organização.
Em segundo lugar, Gramsci desenvolve o uso
do termo "subalterno" com uma referência
específica ao proletariado industrial
avançado, tanto avançado na tentativa de
dar vida a uma própria forma de democracia,
e que, portanto, iniciou um processo não
só de "contra-hegemonia", mas também
de "desafio hegemônico", para a conquista
de hegemonia. Em terceiro lugar, o termo é
usado como referência a sujeitos singulares,
seja em relação à sua colocação social,
seja em relação aos seus limites culturais
(CHAGAS, 2018, p. 03).

Da preocupação e crítica dessa visão de subalternidade, produz-se um racha no interior daquela primeira articulação de acadêmicos latino-americanistas nos Estados Unidos, cuja origem foi a afirmação dos adeptos do que viria formar a crítica 
descolonial - naquele seu momento de fundação - de que aquele coletivo latino-americano de estudos subalternos apenas espelhava o coletivo sul-asiático em seu "apoio dado ao pós-modernismo" (GROSFOGUEL, 2007, p. 02). Grosfoguel (ainda agregou que: "Estes debates tornaram claro para nós que era necessário descolonizar não apenas os Estudos Subalternos, mas também os Estudos Pós-Coloniais" (2007, p. 02). E a materialização dessa necessidade passa pela compreensão e execução dos seguintes pontos:

1) uma perspectiva epistémica
descolonial exige um cânone de
pensamento mais amplo do que
O cânone ocidental (incluindo o
cânone ocidental de esquerda);
2) uma perspectiva descolonial
verdadeiramente universal não pode
basear-se num universal abstracto (um
particular que ascende a um desenho
-- ou desígnio - universal global),
antes teria de ser o resultado de um
diálogo crítico entre diversos projectos
críticos políticos/éticos/epistémicos,
apontados a um mundo pluriversal
e não a um mundo universal; 3) a
descolonização do conhecimento
exigiria levar a sério a perspectiva/
cosmologias/visões de pensadores
críticos do Sul Global, que pensam com
e a partir de corpos e lugares étnico-
raciais/sexuais subalternizados
(GROSFOGUEL, 2007, p. 03).

Muitas das expressões utilizadas para qualificar diferentes espaços geográficos - 'avançado', 'atrasado', 'moderno' ou 'em desenvolvimento' - apontam para uma compreensão das diferenças espaciais a partir de marcos temporais sequenciais. Deste modo, temos uma maneira de conceber as diferenças geográficas em termos de uma suposta linearidade histórica, em termos da posição que uma região do planeta ocupa na evolução linear da história dita mundial. Nesta perspectiva, prevalece uma compreensão espacial que subtrai a contemporaneidade do "Outro", negando-lhe sua alteridade e impondo uma história de narrativa única. Grosso modo, a América Central vista como uma região 
num mundo que pensa o universal, mas não o pluriversal, ainda é o lugar de profundas assimetrias sociais entre os países que a constituem e entre seus povos no interior de cada Estado-nação, permitindo sua caracterização geopolítica, em chave descolonial, como "lumpemregião".

\section{Centroamérica: "lumpemregião"14}

Ao fazermos, neste texto, uma analogia com o termo lumpen, isto é, do âmbito de classe/sujeito sociopolítico para o de uma região geográfica, não estamos inadvertidamente criando neologismos ex nihilo. Ao contrário, tomamos em conta duas considerações teóricas previamente elaboradas por renomados apontamentos:

- As do geógrafo Richard Walker, que se valeu do termo e o conceituou ainda nos anos 1970, a partir dos seus diálogos com a Teoria da Dependência para pensar uma lumpengeografia do capital;

- As do sociólogo Imannuel Wallerstein, desde os anos 1990, que vem trabalhando na relativização da importância de atores nacionais, como as classes sociais, para explicar o caráter e as consequências sofridas por essas classes, não pela sua participação nas relações de produção que definem o âmbito nacional da economia, senão pela sua participação em um sistema mundial de acumulação.

\footnotetext{
14 É porque a América Central, como região, está integrada ao capitalismo internacional que sugerimos essa analogia ao termo lumpen, como realizado muito anteriormente por Richard Waker (1978) para o caso da região de Gales. Centroamérica, como argumentamos, não apenas está integrada ao vigente sistema de acumulação, senão é fundamental para o seu funcionamento por sua condição ístmica, especial e particularmente como periferia subalterna. Isto é, semelhantemente à forma com que Ernesto Laclau (2013) problematiza a assentada ideia de que o lumpemproletariado é desnecessário, é apenas ralé, um estorvo à força e trajetória revolucionário do proletariado, tal como Marx e Hegel postularam para uma classe social, que estabelecemos relação com uma lumpengeografia do capital no caso da América Central. Deixar de entender tal analogia é buscar acomodar criticas deslocadoras de certezas teóricas, como fazem alguns afeitos ao dogma marxista, aos seus terrenos, supostamente sólidos, que desmancham no ar.
} 
Ou seja, a base dessa analogia à região centro-americana precisamente para problematizar a noção de região - é a função que essa acaba cumprindo no presente sistema mundial de acumulação, em que sua posição subalterna e periférica enquanto região não é uma assimetria ou um desvio, senão uma necessidade incentivada e desejada pelo sistema para o seu funcionamento.

A teoria do sistema-mundo de Immanuel Wallerstein (1990) inspirou importantes trabalhos de Walter Mignolo (2003; 2007), por exemplo, e se fez seminal para as possiblidades de questionar a visão que coloca os problemas dos territórios que já foram Terceiro Mundo em termos de atraso com relação a outros países: apesar de alguns estarem à frente, estão todos no mesmo caminho. Sendo assim:

De lo que se trata es que no todos los países van recorriendo el mismo camino en un orden en el que unos se ubican más adelante que otros $y$, por lo tanto, su experiencia sería aprovechable por los que les siguen Lo que ocurre es que el sistema mundial tiene una historia que es recorrida por todos los países al mismo tiempo desempeñando papeles distintos, en una estructura que es contemporánea a todos. De este modo, el centro y la periferia tienen una historia única, que recorren juntos, al mismo tiempo, estructurando y reestructurando sus relaciones. Tomados por separado, como unidades nacionales, la historia de los países del centro no prefigura la historia de los periféricos, son historias diferentes. (RICARDO; YOCELEVZKY, 2013, p. 70 - 71).

Em um sistema internacional dado a partir dos Estadosnação como unidades empiricamente descritíveis da economia, da sociedade e das formas de dominação, estes são estabelecidos como evidência inevitável e natural da realidade. Contudo, no intuito de contribuirmos com uma atualização teórica sobre a Centroamérica, nos ocupamos tanto de afirmar como de problematizar alguns objetos-marcos na teoria social contemporânea, o que significa projetar epistemologias relacionais para a apreensão analítica dos processos sociais e históricos que nomearam a América Central enquanto região: modernidade/colonialidade, 
lutas sociais e, claro, o Estado-nação. Logo, uma interessante analogia ao papel que é esperado da região centro-americana no sistema global emerge quando pensamos na relação e no uso dos termos proletariado e lumpemproletariado no pensamento de Karl Marx, qual seja:

Numa história concebida como a história da produção, a classe trabalhadora seria o agente de um novo estágio no desenvolvimento das forças produtivas, e o termo "proletariado" foi empregado para designar esse novo agente. Com a finalidade de manter suas credenciais como integrante da principal linha do desenvolvimento histórico, o proletariado tinha de ser estritamente diferenciado do "intruso" absuluto: o lumpemproletariado. (LACLAU, 2013, p. 214).

Ou seja, antes de Marx e de Hegel, o termo proletário era um vocábulo pejorado, cumpria o papel semântico negativado que depois das contribuições daqueles dois filósofos passou a ser ocupado pelo termo lumpemproletariado. A história, na visão marxista, seria um relato unificado por uma lógica-mor: o desenvolvimento das forças produtivas, ao qual corresponde, em cada um de seus estágios, certo sistema de relações de produção. Na crítica a essa assunção histórica essencialista, como diria o próprio Laclau (2013), vem à baila o conceito hegeliano de povos sem história como exemplo do tratamento que a heterogeneidade social ${ }^{15}$ recebe quando abordada por uma lógica totalizante: "seu abandono por meio da negação de sua historicidade" (LACLAU, 2013, p. 212).

Daí a trajetória do termo proletário nas análises sociais europeias: de início designava um excesso heterogêneo nas sociedades que, no século XIX, transitavam e afirmavam-se como industriais. O termo estava no mesmo campo semântico de turba e a sua associação à classe trabalhadora demorou a ocorrer, dado que

15 Uma exterioridade que não tem acesso ao espaço geral de representação não possui um espaço comum, em que dois elementos possam se estabelecer como diferentes, mas a qual uma cadeia de equivalências também se opõem. 
suas conotações estavam, inclusive, dicionarizadas como desgraçado, desprezível e vil. (STALLYBRASS, 1998 apud LACLAU, 2013, p. 213). E foi com Marx que a palavra mudou:

É no âmago dessa alternativa que podemos localizar o movimento magistral de Marx, que consistiu em isolar, no interior do mundo da pobreza que a transição à industrialização estava gerando, um setor diferencial que não pertencia aos interstícios da história ao não histórico - mas estava destinado a ser um protagonista histórico fundamental. Numa história concebida como a história da produção, a classe trabalhadora seria o agente de um novo estágio no desenvolvimento das forças produtivas, e o termo 'proletariado' foi empregado para designar esse novo agente (LACLAU, 2013, p. 214).

Coube ao lumpemproletariado fazer-se a palavra que, com a alteração semântica e pragmática de proletariado, assumiria a investidura negativa que caracterizava o seu termo antecedente. Os próprios Marx e Engels engrossaram as vozes que deram o tom com o qual a nova escória deveria ser conhecida: "O lumpemproletariado, nas grandes cidades, é o pior de todos os possíveis aliados. Esta ralé é absolutamente venal e absolutamente desavergonhada" (LACLAU, 2013, p. 215). Logo, na condição inescapável de marginal sua exclusão do social e do histórico também deveria ser inevitável. Para utilizar um exemplo centro-americano, ainda nos anos 1980, Carlos Vilas (1985) já havia demonstrado em seu estudo seminal que, ao contrário da crença marxista, foi de fato o lumpemproletariado que desempenhou papel fundamental na insurreição sandinista, na Nicarágua, em 1979.

Ou seja, se há, portanto, um papel cumprido pelo lumpem, sua exclusão da história não é verdadeiramente possível. Em outras palavras, a distinção entre o interior e o exterior não está dada a priori, nem é tão nítida. Semelhante situação ocorre com uma região na hodierna geografia do capital. Ela é dita pelo vigente sistema de acumulação como dispensável e passível de ser excluída (o produtivo versus o improdutivo), mas, ao fim e ao cabo, tal retórica se revelou como seu contrário: o sistema quer que o 
lumpen - seja ele uma classe ou uma região - seja visto como apagável e indesejável, mas, na verdade, depende e necessita que seu papel para o funcionamento desse sistema seja cumprido. No caso centro-americano, é precisamente enquanto região, especialmente no que tange a ser lugar geoestratégico do comércio da economia global, por ser atalho entre dois oceanos.

O geógrafo britânico Richard Walker (1978), conhecido por seus trabalhos no campo da geografia econômica, foi um dos primeiros a assumir, em diálogo com a Teoria da Dependência, o termo lumpen para sugerir a lumpemgeografia do capital. Sob essa ideia, ele desenvolve a argumentação de que a mobilidade do capital significa o uso da localização como estratégica contra o trabalho, fazendo com que o desenvolvimento local esteja cada vez mais dependente de investimentos externos e gere uma permanente reserva de territórios estagnados.

No que se refere ao nosso tema de estudo, podemos fazer uma analogia com a relação centro-periferia que a América Central encarna em sua condição geopolítica. Essa relação não se dá, a partir de uma essência ou de uma posição particular numa trajetória temporal supostamente linear, mas é, sim, constitutiva do próprio sistema-mundo/moderno-colonial. El marginal de la marginalidad (ARIAS, 1995), é uma das muitas alcunhas que situam a Centroamérica na condição subalterna, como uma região geográfica inteira e não só como um sujeito social. No mundo globalizado, é a periferia que dá centralidade ao centro, um paradoxo semântico que dá sentido à própria lógica da economia política global.

Em um contexto de persistente pobreza e desigualdades, somado a sistemas político-jurídicos com grandes fragilidades marcadas pela corrupção e pela tensão social ocasionada, entre outros fatores, pelas migrações externas e internas, favorecem-se a deterioração do tecido social dos países ístmicos, uma zona que, até meados dos anos 1990, estava imersa em conflitos armados e guerrilhas como consequência, não exclusiva, mas em larga medida, da ambição politica por parte de grandes potências externas que sua posição geográfica provocou. 
Ainda hoje, na América Central, a exploração desenvolvimentista da condição ístmica da sua geografia - estrategicamente conectiva pelas lentes da geoeconomia global - define a vida e a morte de seus territórios e de suas identidades. A falácia do megaprojeto do Grande Canal Interoceânico da Nicarágua (GCIN), por exemplo, foi uma gigantesca manobra de obtenção de controle de terras comunitárias por parte do governo sandinista, que aumentou profundamente a conflitividade nos antigos territórios miskitas, hoje a Região Autônoma do Caribe Sul (RACS) da Nicarágua onde habitam os povos rama-creole. Em nome do desenvolvimento nacional, o marco forçosamente instaurado de concessão de terras para construção e exploração do suposto canal (lei $\mathrm{n}^{\circ} 840 / 2013$ ) outorgou direitos de usos de 52\% daquelas terras historicamente reclamadas por aqueles povos, para a fantasiosa construção do GCIN por uma enigmática empresa chinesa. Com isso, esse projeto se converteu numa das mais simbólicas e atuais expressões da noção de lumpemregião e da ganância extrativista e desenvolmentista na América Central (AGUILAR ANTUNES, 2018).

Os povos desses territórios, entretanto, estão cada vez mais certos de um futuro que não está dado por um destino ou maldição geopolítica ístmica (AGUILAR ANTUNES, 2017), determinada por um tradicional exterior ingerente, senão pela construção dos autorreconhecimentos de seus pluralismos sociais que identificam direitos e os reivindicam. Centroamérica como região se constitui de forma identitária, como contingência e potência, similar e analogamente a esses sujeitos subalternos:

O lumpemproletariado, uma vez constituído, convoca todas as suas forças para pôr em perigo a 'segurança' da cidade e é o signo da irrevogável decadência, da gangrena sempre presente no coração da dominação colonial. Assim, os malandros, os arruaceiros, os desempregados e os pequenos criminosos (...) atiram-se à luta como se fossem destemidos trabalhadores. Esses preguiçosos sem classe, através de uma ação militante e decisiva, descobrirão o caminho que conduz à constituição de uma nação (...). Também as prostitutas e as criadas que ganham duas libras por mês, todos aqueles que giram em círculo entre o suicídio e a loucura, 
recuperarão seu equilibro, avançarão mais uma vez e marcharão orgulhosamente na grande procissão da nação que ora despertou. (FANON, 1965 apud LACLAU, 2013, p. 223 - 224).

A discussão entre o suposto papel regressivo do lumpemproletariado, tradicional e deliberadamente expressa no pensamento marxista d'O 18 de Brumário de Luis Bonaporte, em contraste com seu potencial papel de destituir as estruturas de dominação de poder, tal qual expressado por Fanon (1965), pode ser uma discussão em aberto, mas não é nova. É precisamente nessa esteia que Laclau (2013) caminha e, por isso mesmo, deliberadamente cita este autor, para reforçar sua concordância com o potencial de força de deslocamento do lumpenproletariado, em contraste com a ideia de dispensável e rechaçável impulsionada por Karl Marx. Centroamérica, mais uma vez analogamente, é então uma lumpemregião pelo perigo que efetivamente representa à ordem sistêmica que se quer manter hegemônica.

\section{REFERENCIAS}

AGUILAR ANTUNES, A. Um discurso político ístmico: a integração regional centro-americana entre o significante vazio e a colonialidade do poder. 2017. 349f. Tese (Doutorado em Ciência Política) - Programa de Pós-graduação em Ciência Política, Universidade Federal de Pernambuco, Pernambuco, 2017.

Territorios, identidades y canales: pueblos centroamericanos entre la geopolítica y la cosmopolítica. In: GARITA, N. (ed.). América Latina y sus pueblos en movimiento. Heredia: Letra Maya, 2018. p. 33 - 76.

AGUILAR ANTUNES, A.; VITORINO, J. O pragmatismo da estratégia de segurança e da integração regional centro-americana. In: ENCONTRO NACIONALDA ASSOCIAÇÃOBRASILEIRADERELAÇÕESINTERNACIONAIS, 4., 2013, Belo Horizonte. Anais eletrônicos... Belo Horizonte: ABRI, 2013. Disponível em: <http://www.encontronacional2013.abri.org.br/ resources/anais/20/1370034448_ARQUIVO_Artigo_ABRI_Final.pdf>. Acesso em: 27 jun. 2016. 
ARIAS, A. Descolonizando el conocimiento, reformulando la textualidad: repensando el papel de la narrativa centroamericana. Revista de Crítica Literaria Centroamericana, Lima, a. 21, n. 42, p. 73, 1995.

BALLINA, J. L. Mesoamérica o el Proyecto Mesoamérica: la historia como pretexto. Liminar, Berkeley, v. 09, n. 01, p. 132 - 152, 2011.

BAVIC - Bienal de Artes Visuales del Istmo Centroamericano. Nadie sabe el pasado que le espera: evento teórico. 2010, Managua. Anais eletrônicos... Managua: BAVIC, 2010. Disponível em: <http:// www.bienalcentroamericana.com/documentos/pdf/viiBC_10NIC_ EventoTeorico_catalogo.pdf $>$. Acesso em: 14 mar. 2016.

BERGER, M. G. Istmicidad: persistencia de la historia y estrechos dudosos. In: CONGRESO DE LA RED CENTROAMERICANA DE ANTROPOLOGÍA, 11., 2017, San José. Anais eletrônicos... San José: RCA, 2017.

BERGOEING, J. P. La integración centroamericana en el nuevo milenio. Revista de Geografía Norte Grande, Santiago de Chile, n. 28, p. 105 $112,2001$.

BRIGNOLI, H. P. Breve historia de Centroamérica. Madrid: Alianza Editorial, 2010.

CALDENTEY, P. Panorama de la integración centroamericana: dinámica, intereses y actores. Córdoba: Fundación ETEA, 2010. p. 223 - 259.

CARDENAL, R. Manual de Historia de Centroamerica. El Salvador: UCA Editores, 2014.

CASTAÑEDA, J, G.; VALENZUELA, R. A. Grandes cambios en la pequeña cintura de América. Nexos, [on line]. 01 oct. 2015. Disponível em: <http:// www.nexos.com.mx/?p=26486>. Acesso em: 9 abr. 2017.

CHAGAS, J. O "lugar de fala" nos movimentos: pressupostos teóricos pós-modernos, materialização prática fragmentária. Esquerda Online, [on line], 20 jul. 2018. Disponível em: <https://blog.esquerdaonline. com/?p=8439\#sdfootnote2anc $>$. Acesso em: 30 jul. 2018.

CUEVAS-MOLINA, R. Identidad y Cultura en Centroamérica: nación, integración y globalización a principios del siglo XXI. San José: Editorial Universidad de Costa Rica, 2006.

De banana republics a repúblicas maquileras: la cultura en Centroamérica en tiempos de globalización neoliberal. San José: Euned, 2012.

DABÈNE, O. The politics of regional integration in Latin America: theoretical and comparative explorations. New York: Palgrave Macmillan, 2009. 
ERCA - Programa Estado de la Nación. Primer Informe Estado de la Región en Desarrollo Humano Sostenible. San José: Programa Estado de la Nación, 1999.

ESCOBAR, A. Latin America at a Crossroad: alternative modernizations, post-liberalism, or post-development? Cultural Studies, Routledge, v. 24, n. 01, p. $01-65,2010$.

FANON, F. Studies in a dying colonialism. New York: Grove Press, 1965.

FUENTES-KNIGHT, J. A. Prólogo. In: VALDEZ, F. El gobierno de las élites globales: cómo se organiza el consentimiento, la experiencia del Triángulo Norte. Cidade de Guatemala: Editorial Cara Parens, 2015. p. 09 - 11.

GARITA, N. Los Espacios en Blanco de la Historia: la "Otra" Integración Centroamericana. In: MARTINS, P. H.; RODRIGUES, C. (orgs.). Fronteiras abertas da América Latina: diálogo na Associação Latino-Americana de Sociologia. Recife: Ed UFPE, 2012. p. 149 - 173.

Construcción simbólica de la Centroamericanidad: la literatura de posguerra regional. In: CONGRESO DA ASSOCIAÇÃO LATINOAMERICANA DE SOCIOLOGIA, 24., 2013, Chile. Anais... Chile: ALAS, 2013.

GRANADOS-CHAVERRI, C. Hacia una definición de Centroamérica: el peso de los factores geopolíticos. Anuario de Estudios Centroamericanos, San Jose, v. 11, n. 01, p. $59-78,1985$.

GROSFOGUEL, R. Implicaciones de las alteridades epistémicas en la redefinición del capitalismo global: transmodernidad, pensamiento fronterizo y colonialidad global. In: ZULETA PARDO, M.; CUBIDES, H.; ESCOBAR, M. R. (eds.), ¿Uno solo o varios mundos?: diferencia, subjetividad y conocimientos en las ciencias sociales contemporáneas. Bogotá: Siglo del Hombre Editores, 2007. p. 99 - 116.

GUHA, R. Elementary Aspects of Peasant Insurgency in Colonial India. Durham: Duke University Press, 1991.

LACLAU, E. A razão populista. São Paulo: Três Estrelas, 2013.

LUDDEN, D. Reading Subaltern Studies: Critical Histories, Contested Meanings, and the Globalization of South Asia. London: Anthem Press, 2002.

MIGNOLO, W. Histórias locais-projetos globais: colonialidade, saberes subalternos e pensamento liminar. Belo Horizonte: EdUFMG, 2003.

The rethoric of modernity, the logic of coloniality and the grammar of de-coloniality. Cultural studies, Routledge, v. 2, n. 21, p. $449-514$, 2007. 
MORAÑA, M.; DUSSEL, E.; JÁREGUI, C. (eds.). Coloniality at large: Latin american and the postcolonial debate. Durham: Duke University Press, 2008.

MORIN, E. Para um pensamento do Sul: diálogos com Edgar Morin. Rio de Janeiro: SESC, 2011.

NERUDA, P. Canto general. Buenos Aires: Editorial Seix Barral, 2002.

QUESADA MONGE, R. Keith en Centroamerica: imperios y empresarios en el siglo XIX. San Jose: EUNED, 2013.

QUIJANO, A. Raza, Etnia y Nación en Mariátegui: cuestiones abiertas. In: MORGUE, R. (ed.). Mariátegui y Europa: el otro aspecto del descubrimiento. Lima: Amauta, 1992. p. 22 - 46.

Colonialidad del poder y clasificación social. Journal of WorldSystem Research, Riverside, v. XI, n. 2, p. 112 - 134, 2000.

RICARDO, A.; YOCELEVZKY, R. Immanuel Wallerstein y las ciencias sociales latinoamericanas. Revista Reencuentro, Districto Federal de México, n. 66, p. 68 - 79, 2013.

SALAMANCA, E. Centroamerica, laboratório de la Modernidad. Cuenta Centroamerica Portal Literario, [on line], 12 set. 2014. Disponível em: $\quad<$ http://blog.goethe.de/cuentacentroamerica/archives/37Centroamerica,-laboratorio-de-la-Modernidad.html>. Acesso em: 30 out. 2016.

SALVATORE, R. D. The Postcolonial in Latin America and the Concept of Coloniality: A Historian's Point of View. Caba: Universidad Torcuato Di Tella, 2010.

SANTOS, B. de S. Do pós-moderno ao pós-colonial: e para além de um e outro. Braga: Centro de Estudos Sociais, 2004.

SILVA-HERNÁNDEZ, M. El nombre de Centroamérica y la invención de la Identidad regional In: COLOQUIO INTERNACIONAL CREANDO LA NACIÓN, 2006, Ciudad de México. Anais... México D.F., 2006.

STALLYBRASS, P. Marx's Coat. In: SPYER, C. P. (ed.). Border Fetishisms: Material Objects in Unstable Spaces. New York: Routledge, 1998. p. 23 - 35.

TORRES-RIVAS, E. Interpretación del desarrollo social centroamericano: procesos y estructuras de una sociedad dependiente. Ciudad de Guatemala: Editorial Universitaria Centroamericana, 1981.

Revoluciones sin cambios revolucionarios. Ciudad de Guatemala: F\&G Editores, 2011. 
VILAS, C. M. El Sujeto Social de la Insurreccion Popular: La Revolucion Sandinista. Latin American Research Review, Ciudad de México, v. 20, n. 01, p. $119-147,1985$.

WALSH, C. Las geopolíticas del conocimiento y colonialidad del poder, Polis [online], 4|2003, Publicado 19 outubro 2012. Disponível em: <http:// journals.openedition.org/polis/7138> Acesso em: 22 junho 2019

WALKER, R. Two Sources of Uneven Development Under Advanced Capitalism: Spatial Differentiation and Capital Mobility. Journal Sage, [on line], v. 10, n. 3, p. $28-38,1978$.

WALLERSTEIN, I. O sistema mundial moderno. V. 1. Lisboa: Afrontamento, 1990.

ZAMORRA, C. Centroamérica en su hábitat latinoamericano y caribeño. In: SOTO-ACOSTA, W.; ULLOA, M. (eds.). Centroamérica: casa común e integración regional. Heredia: Universidad Nacional de Costa Rica, 2014. p. $223-239$. 